\title{
Medical humanities: An aid to ethical discussions
}

\author{
Anthony R Moore Department of Surgery, University of Melbourne, Royal Melbourne Hospital
}

'The ethical landscape', the title given to part of a course devised by Mr Moore, is described in full in this paper. The whole course is a new adventure in medical education designed to help students to explore the ethical problems in the practice of medicine. The 'ethical landscape' is seen through discussion based on passages from literature depicting doctors' and patients' dilemmas. As the results summarized in the tables show, the students found the course well worth while, and thought that they had gained a new insight into the problems with which they would be confronted and also into their own personalities and those of their fellow students whom previously they had only known superficially. The Chairman of the course, Mr Moore, was also subjected to assessment from his students, because on the skill of the Chairman such a course would fail or succeed.

POLONIUS What do you read, my Lord?

HAMLET Words, words, words.

In a formal medical syllabus it is difficult to provide an opportunity for the discussion of broader cultural, philosophical and personal issues. Time, utilitarian demands, faculty requirements and the 'scientific-objective' approach all conspire to subvert the ideal of a general education for doctors. In particular, it is a delicate task to create an environment where the students take the intellectual initiative in a consideration of human or ethical issues. In an attempt to provide such an opportunity, I have designed a short course which is structured around a consideration of extracts from classic literary works. Each of the 86 short extracts studied alludes either to the experience of the patient, the doctor's performance or professional behaviour.

Over the past 12 months 79 students have taken the course. A short extract of the details of the course and the students' response has been published recently in the New England fournal of Medicine ${ }^{1}$. It is believed that the course is original in the modern context of medical education. This paper outlines the course and concentrates on the session which deals with medical ethics.

\section{The form and content of the course}

Groups of 13 fourth-year medical students gathered informally in the seminar room at the Department of Surgery, Royal Melbourne Hospital. The students, in their first clinical year, were those or the roster for surgical teaching - a responsibility $\vec{\rho}$ shared by the author-but their challenge on Friday afternoon was quite different.

On arrival, each student took up a number of

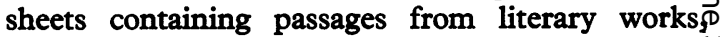
varying in length between a paragraph and a page ${ }_{\vec{\omega}}^{\omega}$ On the front page was a reference list of the pasi sages to be considered under the day's topic. The students had no prior knowledge of the passages but were aware of the topic. No reading beforehand was required. For example, the topic for the thirct week was 'the ethical landscape', and included, extracts from The Masters (C P Snow, 195I); Sons and Lovers (D H Lawrence, I913); $A$ System of Moral Philosophy (F Hutcheson, I755, vol I) ${ }^{N}$ Life of Samuel fohnson (James Boswell, I79I) Medical Ethics (T Percival, 1794-1803); The Scarle Letter (Nathaniel Hawthorne, 1850); Fable of the Bees (B de Mandeville, I705-23, remark 'P') : The Island of Dr Moreau (H G Wells, I896) $\mathbb{D}$ Doctor's Dilemma (George Bernard Shaw, 1906) $\overrightarrow{\widehat{D}}$

After the group had studied the list, they indi $\exists$ cated to me which extract they would like to consider first, and then read that passage silently for a few. minutes. If the passage selected was the one from C P Snow's novel The Masters ${ }^{2}$, the group would read as follows:

'He went into hospital last night. They put a tube down him this morning and sent him home. The results came through just before dinner. It is utterly hopeless. At the very most - they give him six months'.

'What is it ?'

'Cancer. Absolutely inoperable! ...

'Yes, we've heard his sentence', said Jago. 'Bu? there is one last thing which seems to me mores ghastly than the rest. For there is someone who has not heard it'.

He paused. Then he said: 'That is the man himself. They are not going to tell him yet'.

'For some reason that seems utterly inhuman's? said Jago, 'these doctors have not told him. He'so been given to understand that in two or three month? he will be perfectly well. When any of us see him we are not to let him know any different'.

'I hope you've already been told that my husban£ does not realise the true position. He believes that 
the doctors have overhauled him and found him pretty sound. He has been told that he has the trace of an ulcer, and he believes he will soon be well. I ask you to think before every word so that you leave him with the same conviction'.

'It won't be easy, Lady Muriel', I said. 'But I'll try'.

'You will understand that I am already acting as I ask you to act. It is not easy for me'.

There was grandeur in her ramrod back. She did not give an inch.

'I am positive', she said, 'that we are doing right. It is the last comfort we can give him. He can have a month or two in peace'.

'I completely disagree', Joan cried. 'Do you think comfort is all he wants ? Do you think he would take comfort at that price?'

'My dear Joan, I have listened to your views -'

'Then for God's sake don't go on with this farce'.

The girl was torn with feeling, the cry welled out of her. 'Give him his dignity back'.

'He's quite certain he'll soon be well'. Jago said, 'that is the most appalling thing'.

'You would have told him?'

'Without the shadow of a doubt'.

'I'm surprised that you're so convinced', said Winslow, ready to disagree.

'I'm utterly convinced'.

'I don't like to suggest it, but I'm inclined to think that Dr Jago may be wrong'. Winslow glanced round the table. "If I'd had to make Lady Muriel's decision, I think I might have done the same. I should have thought: this will mean for him a few days or weeks of happiness. It's the last happiness he'll get - he ought to have it if it's in my power. Do any of you share my view ?",

" "No", said Jago. "You're presuming where no one has a right to presume". His tone was deep and simple, no trace of awkwardness left. "There are a few things no one should dare to decide for another man. There are not many serious things in a man's life - but one of them is how he shall meet his death".'

\section{Opening the discussion}

When the reading was finished I would open the discussion with a question such as, "What does the passage say ?' 'Do you like or dislike the opinions or characters ?' 'Is the passage true to human experience ?' 'What do you think of the writing' or 'What message is there in the extract for us to take back to the ward or clinic?' In particular, during the ethics session, 'what are the moral dilemmas portrayed in the passage?'

When the discussion on any passage was finished the group would move on to another, considering only as many in a session as were compatible with unhurried discussion. After two hours the session closed. It was quite common for the discussion on the passage quoted above to last for over an hour.

For each of the sessions the form was the same, and the topics considered over the six weeks were: I) the patient's experience of illness; 2) the relatives' experience of illness; 3 ) portraits of doctors in literature: the demands of doctorship; 4) the ethical landscape; 5) hindrances to communication: the patient's expectations; 6) public regard for professional performance - past and present.

The topics were selected to cover the widest possible range of human and medical issues (for which appropriate literary extracts were available), and to achieve the objectives of the course.*

\section{Objectives of the course}

The single most important objective of the course was to allow easy and free-ranging discussions which would stimulate the students' intellectual initiatives and encourage them to formulate and articulate their own points of view. The specific objectives were: I) to offer a forum for the discussion of aspects of doctorship which are untended in the formal syllabus; 2) to draw on the medical heritage which is recorded in literature, social history and philosophy; 3) to assist the ideal of cultural scope in medical education; 4) to expose students to well written 'non-medical' English; 5) to explore non-scientific ways of thinking and their importance in a consideration of human and ethical issues; 6) to heighten sensibility for patient care and professional self-assessment.

\section{Assessment}

At the end of each six-week course the students were given a questionnaire. These were answered anonymously, and were left unopened for eight months until four courses had been completed. All 79 students, who have taken the course so far, have answered the questionnaire which probed their satisfaction with the form and content of the course and the chairman's performance, and made an assessment of the objectives. Only two instructions were given to the students on the questionnaire: first, a plea for complete candour; and second, a statement that their spontaneous comments would be valued as much as the answers they gave to the specific questions asked.

\section{Results}

\section{ATTENDANCE}

At almost every session the attendance was 100 per

*The major source of the extracts was the author's reading in literature for research on a thesis entitled 'Attitudes in literature towards the medical profession: 1500 to 1900 '. 
cent. No student was absent from a session without displaying the courtesy of letting the chairman know in advance.

\section{ENTHUSIASM AND RANGE OF DISCUSSIONS}

The large number of students in each group, and the wide range of extracts available for consideration, both contributed to the vigour, enthusiasm and eagerness of the discussions.

Because a sample of the general discussions stimulated by the course has been reported earlier ${ }^{1}$, I shall concentrate on the session which dealt with the ethical landscape. As the sessions were tape recorded, transcripts were available for analysis and documentation. The following is a list of some of the students' questions and comments stimulated in one session alone by the passage from The Masters.

\section{Students' questions -}

How much should a patient be told about the nature of his illness or prognosis?

How important is a general rule in this area, and how important are the details of the particular context and character of the patient in making this decision?

Should a doctor ever lie to a patient ? Is there a difference between a lie of omission and a direct lie?

What does a doctor do if the relatives ask the doctor not to tell the patient, believing that it's in his best interest, but the doctor feels the opposite ?

Do the rights of the patient stand above the rights of the relatives?

What are the problems created when the relatives know the prognosis but the patient remains in ignorance-how artificial is the situation created?

If there is an area of doubt in what you should tell the patient should one err on the side of optimism?

Should one ever put an exact time on the prognosis of a patient? And if you don't, how do you handle the situation where a patient continues to ask, 'How long will it be'?

Do all patients really have an inner sense that they're dying when their prognosis is hopeless ?

Would you ever offer information when a patient hasn't specifically asked?

Should a doctor ever avoid a patient who directly asks them a question such as, 'Am I going to die ? Do I have cancer ?'

Should a doctor ever presume that a patient would not be able to adapt to some distressing news or a bad prognosis ?

Does one's approach to telling a patient about a fatal prognosis depend on the underlying condition or not?

What are the advantages of having the relatives fully informed, particularly in terms of the support they can give to the patient ?
In dealing with a moral problem do we draw distinction between the morality of motivation, the morality of means and the morality of consequence If we're convinced that someone is doing something: for a noble motive, are we tolerant of an evi⿺ consequence?

Do the rights of the patient include the right to be told?

Does the patient's right to be told imply compulsion on the doctor to tell him?

Have times changed so that the patients are better informed and want better information $\Phi$ Should our tendency be a little more towards the 'telling' school rather than the 'non-tellings school?

How does a general practitioner handle situation where a patient wants reassurance, and although the doctor is almost certain (on the basis of his examination and tests) that the patiens doesn't have anything serious, he can't be absolutely certain ?

Does medical research cause a hardening relation to sympathy for human suffering ?

Does medical research produce a preoccupation with results and scientific data at the expense of human compassion? Does a clinical scientific study decrease or increase one's 'spiritual' view of life

Can we ever justify waiving the concept of consen in relation to experimentation?

\section{- and comments}

'Give the patient all the information, and the $\vec{B}$ will pick and choose what they want to hear out of what you've said, and they will believe what they' like to believe out of what you've said. They wil adjust according to their own needs'.

'You don't really need a code of ethics, all yo need to do is to be sensitive when you approach the patient and not shy away. They will ask you what they want to know. They will indicate to you how much they want you to tell them'.

'Often a relative feels guilt in this situation, and tends to express this guilt in a last heroic effort of the patient's behalf'.

'Occasionally the patient's rights infringe on the doctor's rights. But the doctor's decisions will influence the patient to a much greater degree because the patient is not in the same position of power in relation to the doctor. It is the patien? who needs protection'.

'It's my opinion that there shouldn't be a lavi because it would influence the doctor's judgment as' to whether or not he told, and how he told, the patient. He might really press it to make sure the patient knows he's going to die without thinkin? about how he's telling him or what the consequences of telling him will be. The doctor might be in the position of having to rush to make sure he tells the patient some bad news before the patient gets in witto his legal complaint'. 
'Professional trust seems to me to be based on candidness. As soon as you start deceiving a patient you're breaching professional trust. If a doctor does that, what comeback does the patient have?'

\section{COURSE CONTENT}

Over 90 per cent of the students thought the course was interesting, stimulating and relevant to doctorship. The topics chosen were thought satisfactory by 87 per cent of the students, and the most popular topics were the patient's experience of illness, the ethical landscape and hindrances to communication.

Additional topics were suggested by a quarter of the students, and in order of frequency they included: a student's role and responsibilities in a hospital; specific ethical issues such as abortion, euthanasia and dying; relationships between the different sections of the profession and with nonprofessionals; and the politico-medical role of doctors. The students suggested the following modifications to the study passages: fewer passages and longer time for discussions; more time to read them, particularly those from earlier centuries; the addition of some modern passages ( 67 per cent were before 1900); more detail of their literary context; the addition of some humorous ones; and the inclusion of some passages on basic human issues. Additional student comment on the content of the course is given in table $I$.
FORM OF THE COURSE

Student satisfaction with the form of the course is presented in table II.

\section{CHAIRMAN'S PERFORMANCE}

The questionnaire probed the students' satisfaction with the performance of the chairman. The results are given in table III.

Students' comments on the details of the chairman's biases were: he was against the materialistic aspects of doctorship; he would say 'that's very perceptive' when a student said something with which he agreed; he occasionally allowed distortion by letting the articulate students have their say; and, he had his biases, but they seemed very reasonable to me!

\section{OBJECTIVES}

Sixty-four per cent of the students were stimulated either frequently or occasionally to read the original works from which extracts had been taken. The course was felt to deal with original areas by 96 per cent of the students, and 83 per cent felt that the course challenged them to think and articulate their opinions on previously unconsidered topics. Eightyfour per cent of the students had further discussions on the topics with their fellow students and 58 per cent with non-medical friends.

Table IV gives some results in relation to the medical relevance of the course.

Table I Student comment on course content

\begin{tabular}{|c|c|c|c|}
\hline \multirow[b]{2}{*}{ Question } & \multicolumn{3}{|c|}{ Response (\%) } \\
\hline & Yes & No & $N / A$ \\
\hline $\begin{array}{l}\text { Should extracts from the popular press be added to the forum? } \\
\text { Should extracts suggested by students be added to the forum? } \\
\text { Should specific patients whose problems illustrate the topic be } \\
\text { presented at the session? } \\
\text { Should relevant television interview tapes be added to the course? }\end{array}$ & $\begin{array}{l}68 \\
89 \\
71.5 \\
32\end{array}$ & $\begin{array}{l}26.5 \\
7 \\
28.5 \\
68\end{array}$ & $\begin{array}{l}5.5 \\
4 \\
-\end{array}$ \\
\hline
\end{tabular}

Table II Form of course

\begin{tabular}{|c|c|c|c|}
\hline \multirow[b]{2}{*}{ Question } & \multicolumn{3}{|l|}{ Response (\%) } \\
\hline & Yes & No & $N / A$ \\
\hline Was the small group 'round table' form suitable for the session? & 96.0 & 4.0 & - \\
\hline Should students be asked to chair a topic? & 22.5 & 77.5 & - \\
\hline $\begin{array}{l}\text { Should students be offered the chance to present or chair a topic ? } \\
\text { Should non-medical persons (ethicists, historians, behavioural scientists) }\end{array}$ & 88.5 & 11.5 & - \\
\hline be invited as guest chairman? & 43 & 53 & 4.0 \\
\hline What is the maximum number you feel should be in the group? & $\begin{array}{l}\text { Average } \\
\text { Range } \\
\text { Actual }\end{array}$ & $\begin{array}{l}11 \\
6-20 \\
13\end{array}$ & \\
\hline Was the duration of two hours? & $\begin{array}{l}\text { Too long } \\
\text { Too short } \\
\text { Adequate }\end{array}$ & $\begin{array}{c}19 \\
9.5 \\
71.5\end{array}$ & \\
\hline Which medical years is the most suitable for this course ? & Fourth year & 90.5 & \\
\hline
\end{tabular}




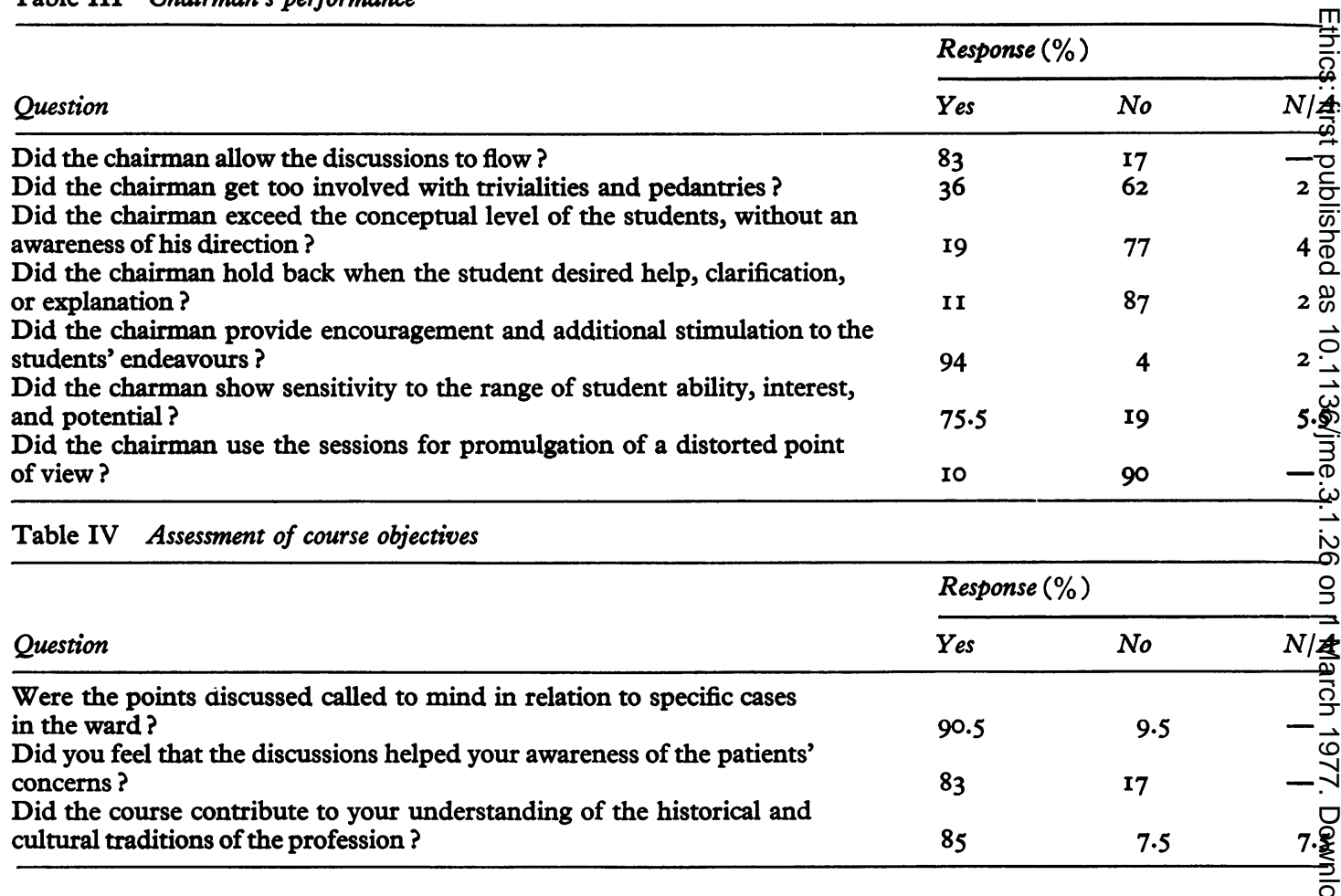

\section{STUDENT TENSIONS DURING THE COURSE}

At some time during the course, 37 per cent of the total student number felt either tense, suspicious, anxious or threatened. For over a half of these students the feelings got less as the course progressed. Students' comments on the details of their tensions included: a dislike of being directly asked a question; an uneasiness if the discussion changed direction so quickly that a thought could not be spoken; a disquiet if it was felt other students knew more; and some tension due to the nature of the subjects, the intensity of the discussion and the chairman's demands. One student claimed that 'being fairly introverted, I don't enjoy talking to groups'; another 'I felt tense but it was not unpleasant - a bursting of sorts'; and another, 'Yes, I felt tense, and threatened, but that was not bad. I felt I had to learn to start thinking again!'

GENERAL COMMENTS OF THE STUDENTS ON THE COURSE Throughout the course the chairman was aware of the students' spirit of commitment to what was going on. The students offered the following general comments on the questionnaire:

'The sessions have been a very intense experience'.

'Six weeks was just right, the experience was beginning to lose its punch'.

'I am a passive student - the sessions helped me'.

'The quality of the teacher is vital to the success of this type of course'.

'I found the course an intrusion - it dealt with matters I felt I could cope with better on my ow and forced me to participate in group activity which I prefer to avoid'.

'The course has given me a greater respect for $m$ 일 fellow students, some guys who I haven't really ever spoken to had ideas which really made me thinkof

'For once I could speak out and feel I was being listened to'.

'Whilst it hasn't stimulated me to read on thie topics discussed, it has stimulated me to read more on other non-medical topics which interest me'.

'The object of the course centred around more con? cern for patients' needs, and I think this is very valide

'My biggest pleasure was sitting down wit interesting, intelligent people discussing ideas for the first time in years'.

Ninety-eight per cent of the students recom? mended the course to the incoming students, ands more significantly, 87 per cent of the students want second course, dealing with different topics in similar fashion, to be organized for later in theif course.

\section{Discussion}

The importance of cultural breadth in the educatio of doctors has been a favourite topic for gues orations and journal 'points of view'. In an earlie paper I outlined the philosophical argument for medical humanities course. ${ }^{3}$ This paper describe what is thought to be an original course, designed 
to put that ideal into practice, and to relate the educational experience to patient care. Alan Gregg's vehement comment captures these two principles:

'... it is uncomfortable to see how meagre is the cultural baggage, how callow the manners, how unexercised the imagination and sympathies of our medical students must remain unless we open them to the resources of humanism.... How can we expect such a one to have the valences that will enable him to combine effectively with patients in the bewilderment and loneliness and anxieties of illness".'

Commenting on the obscurity of much medical writing, Dr F J Inglefinger suggested:

'The only hope, and perhaps a faint one, is to encourage the student and graduate in medicine to take up serious non-professional reading. Medical school curricula might benefit by less periodic reshuffling and by greater efforts to make sure students read works like Arrowsmith, The Magic Mountain and Cancer Ward ${ }^{5}$ '.

The study of literature for 'medical' reasons has been recommended by others: The Abnormal Personality through Literature ${ }^{6}$, by Stone and Stone, recognized Freud's view that 'imaginative writers are valuable colleagues. ... In the knowledge of the human heart they are far ahead of us common folk, because they draw on sources that we have not yet made accessible to science'. Spradlin ${ }^{7}$ used dramatic works as an adjunct to teaching human behaviour; and the London Medical Group has recently considered Man in Literature at one of their seminars. Long and others used literature as illustrations in Conflict in the Classroom: Education of Children with Problems ${ }^{8}$, and Tavuckis and colleagues have produced a book called The Family through Literature ${ }^{9}$.

The results of this course suggest that the study of literary, historical, and philosophical passages can stimulate students to broaden the cultural breadth of their education in an enjoyable way; and can offer a method of making a study of human behaviour relevant to their experience as medical students. I was convinced of the great advantages of being able to relate the human issues in the literary works to patients seen by us all in the ward. This overcame the problems of relevance and credibility which concern all 'non-clinical' behavioural scientists.

Studying the attitudes and experiences of patients and doctors who appear as characters in a literary work offers considerable freedom. Students could respond to individuals in fiction without the embarrassment or liabilities of a 'personality attack' which are inherent in an appraisal of a real-life person - a point made by Jones ${ }^{10}$ in relation to moral education. I chose the ethical issue of 'what to tell the patient' rather than the more commonly discussed topics of abortion, euthanasia or transplantation. The specific issue is irrelevant (we could have used the passage from D H Lawrence's novel Sons and Lovers which deals with euthanasia), for a study of ethics should explore the way we react to moral dilemmas, and should provide a rational framework for understanding the complexities of moral judgment rather than offer specific guidance or rules of conduct.

Students were able to explore wider issues, free of a preoccupation with the specific 'medical' aspects of a case. The course drew on the medical history contained in non-medical works - the value of which has been noted by others ${ }^{11}$.

I am uncertain how much the success of the course was dependent on my educational background in both humanities and medicine. It is felt that once the extracts have been assembled, judicious qualities of chairmanship such as enthusiasm and sensitivity, which allow the students to emerge, are more important than scholastic abilities. Obviously the point is crucial to the general relevance of the course in medical education. I am willing to make available all the study passages to other interested doctors who intend to try the course.

Whether the study of such literary works for a medical end is justifiable on literary grounds is a delicate point. If it isn't the students showed that there was still 'medical' validity in the exercise. But the author believes it is; for, given the chance, medical students showed themselves quite able to make value judgments on the quality and techniques of literary writing.

Obviously, literature is unly one dimension of the humanities. At the time of writing the chairman is adding a visual element to the verbal structure of the course. Paintings and portraits relevant to the topics are being shown as slides, and are being discussed according to the same general approach outlined in the paper. On the whole, the paintings are offering an additional scope for individual interpretation and response, and are a valuable supplement to the relatively analytical approach to the written word.

One additional advantage of the course is that it could be adapted for any group of allied health professionals.

From the chairman's point of view the sessions have been rewarding, exciting and exhausting. The large number of students in a group guaranteed the sort of interaction which only comes with multiple opinions, and it was uncommon for the chairman to have to 'generate' discussion. But the principle of guaranteeing that all opinions were heard, and that all students felt confident to speak, was very demanding.

It is hoped that the issues discussed, and the books read, will aid the students' endeavour to be better doctors and more cultured people. But no claim is made for a long-term effect. The course has been designed to stimulate questions rather than to provide answers. 


\section{Acknowledgements}

The author would like to thank Dr Theodore Redpath, Fellow and Director of English Studies, Trinity College, Cambridge University, who offered the seed; and Professor Maurice Ewing, Department of Surgery, University of Melbourne, who provided the soil.

\section{References}

${ }^{1}$ Moore, A R, Medical humanities: A new medical adventure, New England fournal of Medicine, 1976, 295, 1479-80.

2Snow, C P, The Masters, Penguin Books, 195I.

${ }^{3}$ Moore, A R, The art of medicine: A missing subject, Medical fournal of Australia, 1975, 2, 27-8.

${ }^{4}$ Gregg, A, Humanism and science, Bulletin of New York Academy of Medicine, I94I, 83-99.
'Inglefinger, F J, 'Obfuscation' in medical writing, $N e p$ England fournal of Medicine, 1976, 294, 546-7.

'Stone, A A, and Stone, S S, The Abnormal Personalit through Literature; Prentice Hall, Inc, New Jersey 1966.

'Spradlin, W W, Drama as an adjunct to teaching humai behaviour, fournal of Medical Education, 1966, 4⿳一巛工 377-80.

${ }^{8}$ Long, N J, Morse, W E, and Newman, R G, Conflict to the Classroom: Education of Children with Problems. Wadsworthy Pub. Co. Inc., Belmont, Californiw, 1965.

${ }^{\circ}$ Tavuchis, N, and Goode, W J, The Family Throug $\vec{g}$ Literature. McGraw-Hill Book Co, USA, 1975.

${ }^{10} \mathrm{Jones}, \mathrm{C}$, The contribution of history and literature $\overrightarrow{\mathrm{E}}$ moral education, fournal of Moral Educations 197,5 27-38.

${ }^{11}$ Agnew, L R C, and Harvard, A M, Medical historỳz Profession or pastime ?, Lancet, 1957, 2, 432-4. 